\title{
Convencionalidad y medidas cautelares. Protección de comunidades indígenas ${ }^{1}$
}

Convencionality and interim reliefs. Protection of indigenous communities

Jairo Adolfo Calderón Mora ${ }^{2}$

Fecha de recepción: 15 de mayo de 2015

Fecha de aprobación: 30 de junio 2015

\section{RESUMEN}

Con la aparición del Sistema Interamericano de Derechos Humanos en el siglo XX y la Convención Americana, se fortalece la protección coercitiva de los derechos humanos, a través del ejercicio del denominado control de convencionalidad que ejerce la Corte Interamericana de Derechos Humanos. Lo anterior supone por los Estados miembros del Tratado Constitutivo de la Corte Interamericana de Derechos Humanos, garantizar los contenidos del citado tratado

La metodología empleada en las presentes líneas fue cualitativa en el marco del método descriptivo.

Palabras clave: convencionalidad, medidas cautelares, propiedad comunal, garantía constitucional.

1 Artículo vinculado al proyecto de investigación "Medidas cautelares en la Comisión Interamericana de Derechos Humanos", para obtener el grado de magister en Derechos Humanos y Derecho Internacional de los conflictos armados de la Escuela Superior de guerra.

2 Magister en Derechos Humanos y Derecho Internacional de los Conflictos Armados, funcionario de la Fiscalía General de la Nación y docente de la Universidad Militar Nueva Granada. Correo electrónico: jairocalderon@ gmail.com 


\section{Abstract}

With the advent of the Inter-American Human Rights in the twentieth century and the American Convention, the enforcement of human rights protection is strengthened through exercise called conventionality control exercised by the Inter-American Court of Human Rights. This implies by the Member States of the Treaty establishing the Inter-American Court of Human Rights, ensure the contents of that treaty

The methodology employed in these lines was under the qualitative descriptive method.

Keywords: Convencionalidad, measures you will protect, communal property, and constitutional right. 


\section{INTRODUCCIÓN}

En el proceso de consolidación de los tribunales y jueces constitucionales, se observa un cambio de mentalidad por encontrar valor a la garantía judicial para la protección de los derechos humanos. En el marco de la citada temática, la justicia transnacional se constituye en valor simbólico de los Estados, los cuales se deben comprometen a una mayor flexibilidad de propender derechos en el orden normativo y jurisprudencial.

Desde la citada perspectiva, y descendiendo al tema de interés de las presentes líneas, es indispensable el reconocimiento a los derechos conexos con la propiedad ancestral, desde la perspectiva de la Comunidad Interamericana de Derechos Humanos.

\section{Poder JUdicial - garantía constitucional}

Con la concepción de la jurisdicción, acción y proceso se parte de la idea que la función judicial es una garantía constitucional. En este sentido Gozaini (2006) declara:

La teoría general del proceso acepta contener tres preocupaciones esenciales: la jurisdicción, que significa atender al rol del juez en el proceso, las garantías judiciales que se debe impartir en su magisterio, la organización jurídica de un país o región, y los deberes que supone el ejercicio jurisdiccional. La acción, es el terreno del acceso a la justicia; allí anidan las preocupaciones del que pide y reclama, donde se atienden situaciones como las condiciones y presupuestos de la demanda, los requisitos para ser parte de un litigio, la defensa técnica en el proceso, la igualación económica con el carente de recursos, etcétera. Finalmente, el proceso o el conjunto de reglas para recorrer el laberinto de las formas procesales, principios que deben cubrirse, deberes y derechos de las partes en orden de producción probatoria, intervención de terceros, y muchos aspectos más que se relacionan también en temas constitucionales (defensa de un juicio, sentencia fundada, derecho a la verdad, plazos razonables en el trámite, nulidades por dilaciones indebidas, doble instancia, libertad personal (p. 24). 
El poder judicial nace como una garantía declarada en una constitución (Dromi, 1992). En este sentido, el juzgador pese a sus críticas de activismo judicial, fluye como el autómata del tercer poder del ciudadano; y se constituye como el protagonista de conceder derechos y el abanderado en la supremacía de la constitución y el intérprete, hermenéutico del orden jurídico.

La herramienta metódica que utiliza el juzgador son fundamentalmente: a) control difuso de constitucionalidad, b) control concentrado de constitucionalidad.

El primero de ellos nace bajo lo que se conoce como el constitucionalismo moderno con la revolución norteamericana. En este sentido, Sagúes (2002), con relación al mencionado control ha declarado:

La tesis afirmada por Hamilton, explica que la constitución de los Estados Unidos de América era "limitada" (en el sentido de que contiene ciertas prohibiciones expresas aplicables a la autoridad legislativa), y que esas limitaciones al parlamento solo puede mantenerse en la práctica a través de los tribunales de justicia, cuyo deber ha de declarar nulos todos los actos evidentes a la constitución que puedan ser válidos. Para Hamilton, esa facultad de la magistratura judicial no implicaba quebrar la tesis de la división de los poderes, ni augurar la supremacía del orden judiciario sobre el legislativo, a fin de cuentas la interpretación de las leyes es propia y peculiarmente de la incumbencia de los tribunales: a los jueces correspondía entonces interpretar la ley suprema y la ley ordinaria; y de haber una discrepancia entre ambas debe preferirse, como es natural, aquello que posee fuerza obligatoria y validez superiores; en otras palabras, debe preferirse la Constitución a la ley ordinaria (p. 41).

Lo dispuesto anteriormente supone un vínculo en la obligatoriedad del precedente constitucional el stare decisis frente a los jueces de inferior jerarquía legal. Los precedentes constitucionales que aunque no fueran formalmente vinculantes con obligatoriedad de iure, para los demás jueces tienen también el carácter de razonamientos jurídicos con autoridad. La fuerza normativa de todos los precedentes, aun aquellos que no son obligatorios de iure, tiene que ser distinguida de lo que 
podría llamarse razones sustitutivas, cuya fuerza depende meramente de su contenido y no de su origen. Todo esto tiene consecuencias interesantes para el sistema jurídico.

Ahora bien, es pertinente anotar que el juez al basar su decisión entre la acción y el proceso, no encuentra solamente senderos legales, eficaces, justos, entre el impacto social de su decisión y los ejes de la política, multiculturalismo, bioética, educación, salud, etc. Lo anterior obedece a la naturaleza misma de la interpretación constitucional de las cláusulas abiertas que facultan al juez para optar entre varias interpretaciones, recurriendo a fuentes o valores no explícitos en el texto constitucional. Para el efecto, Bobbio ha considerado al derecho judicial, es decir el derecho elaborado por los jueces en su tarea permanente de adaptación de la ley a las necesidades concretas de la sociedad (Bobbio, 1992).

Lo anterior permite deducir que los fenómenos sociales se marcan en la constitucionalización de las normas legales, irradiando un paradigma en el derecho de un common law. Lo anterior por el triunfo del control judicial frente a los estamentos orgánicos del Estado, y a la existencia de un derecho de jueces bajo la garantía judicial de inaplicar la ley cuando se afecte la constitución. Para el efecto, "los jueces están inmersos en la tradición del discurso constitucional, y su labor se dirige a evaluar la conducta estatal bajo las normas constitucionales" (Comella, 2011, p. 40).

El derecho continental europeo no fue ajeno a esta medida. Como derecho continental europeo, entiéndase a éste como el sistema jurídico derivado de aquel aplicado en Europa Continental, cuyas raíces se encuentran en el derecho romano, germano y canónico y en el pensamiento de la Ilustración, y que es utilizado en gran parte de los territorios europeos y en aquellos colonizados por estos a lo largo de su historia; éste se suele caracterizar porque su principal fuente es la ley, antes que la jurisprudencia, y porque sus normas están contenidas en cuerpos legales unitarios, ordenados y sistematizados (códigos). 


\section{Garantía Judicial, supranacionalidad y Derechos Humanos}

En la actualidad la garantía judicial pese a estar obedecida en el mandato nacional, exige hoy un mayor compromiso, y en este sentido, Bidart (1994) declara:

Cuando en 1945 los derechos humanos suben de nivel porque ya no van a ser una cuestión exclusiva del derecho interno, en un peldaño más arriba van a ser una cuestión del derecho internacional y de la jurisdicción internacional. Entonces, si el derecho internacional y la jurisdicción internacional se ocupan y se preocupan por los derechos humanos, no es raro que se diga que el hombre, cada uno de nosotros, la persona a su modo es ahora un sujeto del derecho internacional, sui generis, distinto a los estados que han sido y siguen siendo los sujetos clásicos del derecho internacional: pero también el hombre, la persona humana, es hoy un sujeto del derecho internacional. Cosa que se ve no solo cuando tratados internacionales contienen una declaración de derechos, que antes era una cuestión propia de la constitución de cada estado, no solo por eso sino porque también -según sistemas- cuando un estado hace parte de un tratado sobre derechos humanos y viola esos derechos que consigna el tratado en perjuicio de una persona que forma parte de su población, es posible según los sistemas llevar a una queja o una denuncia contra su estado imputándole haber violado en su perjuicio o en la otra persona uno o más derechos consignados en el tratado. Allí se ve la personalidad internacional del hombre, el carácter de sujeto de derecho internacional (p.175).

De lo anterior se deriva que pese a la protección jurisdiccional constitucional local por parte de los Estados, hay claros compromisos de la protección del poder judicial a un derecho supranacional, lo que permite afirmar la consolidación de una justicia constitucional a una justicia supranacional, donde el individuo tenga mayores garantías judiciales

Quiroga (2005) declara:

El derecho a ser oído requiere la determinación de los derechos de inocencia

o culpabilidad de una persona que se tome por un tribunal competente, 
independiente e imparcial establecido con anterioridad a la ley. Cualquier órgano del Estado que ejerza funciones de carácter materialmente jurisdiccional, tiene la obligación de adoptar resoluciones apegadas a las garantías del debido proceso legal (p. 293).

Así el juez ya no solo toma en cuenta la reserva sumarial de su orden constitucional sino se ve inmerso en precedentes, no solo de sus cortes sino de cortes transnacionales que desdibujan cómo proyectar la garantía judicial, ya bajo principios como pro homine, en el cual toda norma más beneficiosa se interpreta a favor de la persona y principios como el ius congens, que significa el conjunto de normas imperativas, indisponibles e inderogables, esto es un bloque de cláusulas pétreas que se denomina bloque de convencionalidad, proyectada por el juez a la aplicabilidad del caso, que se suma a la constitución de los tratados de derechos humanos y a las opiniones consultivas, medidas, recomendaciones para salvaguardar la garantía judicial efectiva de las personas.

Esta teoría sienta los criterios que permiten afirmar una integración competencial de los ordenamientos que descansen en el respeto del principio de soberanía estatal y la cláusula de apertura de las constituciones nacionales, en concordancia con las obligaciones internacionales asumidas por los Estados en los tratados de los cuales son parte. Así, estos desarrollos internacionales, normativos y jurisprudenciales, con respecto a los tribunales nacionales se encuentran en una relación de cooperación, orientada a la protección efectiva de los derechos fundamentales y las personas sometidas a su jurisdicción - de iure y de facto y de orden democrático-constitucional; es decir ratione personae.

Lo anterior permite un reconocimiento en la escala de la validez jurídica donde la garantía opera en dos ámbitos ascendentes, y en donde el juez no se limita a obedecer un precedente único sino abarcar en la totalidad de la universalidad constitucional y los derechos humanos, la solución posible al hecho particular, obedeciendo a un mandato estricto de internacionalización del derecho procesal constitucional, siendo su eje temático y permisivo los derechos humanos. 
Ferrer (2010) declara:

Por otra parte, también se advierte esta constitucionalización del derecho internacional de los derechos humanos a través de principios o de criterios hermenéuticos. Así, se han constitucionalizado los principios pro homine y pro libertatis reconocidos en el pacto de San José; o bien se han utilizado por las jurisdiccionales nacionales. También se advierte la tendencia de incorporar cláusulas abiertas, de recepción de la normatividad convencional o cláusulas constitucionales para interpretar "de conformidad" con los instrumentos internacionales en esta materia (p. 172).

\section{ConTROL DE CONVENCIONALIDAD: DIFUSO}

Gracias a la consolidación del derecho internacional público con la creación de las Sociedad de las Naciones y posteriormente con la organización de las Naciones Unidas, se crea un efecto jurídico normativo a los denominados tratados multilaterales.

De la Guardia (1997) señala:

Se entiende por tratado multilateral todo tratado que con arreglo a sus estipulaciones de un instrumento conexo, ha sido abierto a la participación de cualquier Estado sin restricción o de un considerable número de partes, y que tiene por objeto declarado establecer normas generales de derecho internacional o tratar de un modo general cuestiones de interés general, no solo para las partes en el tratado sino también para otros Estados (p. 53).

Los Estados al reconocer la necesidad de la protección única, derecho pro tempore, formulan la Declaración Universal de los Derechos Humanos, el Pacto de los Derechos Civiles y Políticos y el Pacto de los Derechos Económicos, Sociales y Culturales, creando una codificación internacional en procura de la defensa de los derechos humanos. 
Lo anterior genera un efecto mediático con la necesidad de una convención como cuerpo orgánico y sistemático de normas relativas a una rama del derecho, por oposición a la mera recopilación clasificada por materias cronológicas de leyes.

Fue imperiosa la Convención de Viena de 1969 para la regla de los tratados, pues este trae una serie de elementos que juegan en la universalización de los derechos humanos: a) pacta sunt servanda, todo tratado en vigor obliga a las partes y deben ser cumplidas por ellas, de buena fe; b) primacía del derecho internacional. El derecho interno y la observancia de los tratados, una parte no podrá invocar las disposiciones de su derecho interno como justificación del incumplimiento de un tratado.

Estas dos reglas son imperativas y son universalmente reconocidas en el derecho internacional. Las premisas positivas enunciadas permiten deducir que un tratado suscrito por un Estado debe ser cumplido y obedecido, independientemente del contenido de las reglas de su ordenamiento a menos de ser considerado responsable internacionalmente, con las consecuencias jurídicas al respecto.

En este orden de ideas, existe una nueva rama del derecho internacional de los derechos humanos con la convención de Roma o convención Europea de 1950 para la protección de los derechos humanos y las libertades fundamentales, y cuyo antecedente es la Convención de derechos humanos por el cual se acepta la competencia contenciosa de la Corte Interamericana de Derechos Humanos.

La citada Corte desarrolló la teoría que se puede denominar garantía convencional en el control de convencionalidad, siendo sus datos mediáticos jurídicos el derecho continental europeo, y que en ultimas pretende igualar los efectos de sus fallos a los fallos de los Estados miembros.

Ferrer (2010) afirma:

La Corte Interamericana puede resolver casos contenciosos sometidos a su consideración, atendiendo su calidad de guardián interprete de la Convención Americana. Es en realidad un control concentrado de convencionalidad, al encomendarse a dicho órgano jurisdiccional la facultad exclusiva de 
garantizar el goce al lesionado en su derecho o libertad conculcados y reparar las consecuencias de la medida o situación que se configurado la vulneración de esos derechos y el pago de una justa (p. 173).

La Corte Interamericana de Derechos Humanos, realiza un control de compatibilidad abstracto y concreto entre: el acto, el hecho generador y el daño (sentido lato) con referencia a la $\mathrm{CADH}$ y sus protocolos adicionales, concluyendo si el Estado es infractor o responsable internacionalmente por las acciones $\mathrm{u}$ omisiones de sus órganos, o funcionarios, o particulares con aquiescencia del Estado. Es así que la CIDH sanciona al Estado, mas no a las personas, predicándose una solidaridad compartida de medios y de resultado por el hecho lesivo de la vulneración del derecho humano del ius cogens.

$\mathrm{La} \mathrm{CIDH}$, ha adoptado la doctrina anglosajona donde el juez no solo aplica al caso concreto la interpretación de su carta magna como garantía constitucional, sino la garantía convencional. Lo anterior implica reconocer la fuerza normativa de tipo convencional, que se extiende a los criterios jurisprudenciales emitidos por el órgano internacional que los interpreta. Este nuevo tipo de control no tiene sustento en la $\mathrm{CADH}$ sino que deriva de la evolución jurisprudencial de la Corte Interamericana de Derechos Humanos.

La garantía convencional es extensa por el principio pro homine, se resume en una escala jerárquica de precedente obligatorio para los jueces inferiores de cualquier Estado o nación que haya ratificado la $\mathrm{CADH}$ y la competencia contenciosa de la $\mathrm{CIDH}$, haciendo un hibrido entre la jerarquización normativa de la $\mathrm{CADH}$ y la aplicación del tratado y del precedente.

Albanese (2011) afirma:

La importancia de la aplicación directa de los tratados internacionales de derechos humanos interpretados por los órganos con aptitud de obrar cuando se trata de temas donde existe una línea jurisprudencial que contribuye a la efectividad de los derechos se transforma en un deber ineludible. Cuando una ley interpreta o un acto administrativo ensombrece el camino trazado por la 
jurisprudencia internacional, los jueces deben aplicar la convención, como lo han llevado en numerosas oportunidades, dejando de lado aquellas normas o actos administrativos que lesionan derechos y garantías de las personas en virtud del instrumento internacional correspondiente. Reiteramos que con amplitud de enfoques el control de convencionalidad por parte de los jueces nacionales deben albergar principalmente aquellas pautas jurisprudenciales que fueron resultante de un consenso interpretativo de los integrantes del tribunal internacional (p. 17)

Lo anterior significa que los jueces no son simples aplicadores de la ley nacional, sino que además tienen una obligación de realizar una interpretación convencional, verificando si dichas leyes que aplicarían a un caso particular resultan compatibles con la $\mathrm{CADH}$; de lo contrario su proceder sería contrario al artículo 1.1 de dicho tratado.

El derecho internacional de los derechos humanos tiene por fin proporcionar al individuo medios de protección de los derechos humanos reconocidos internacionalmente frente al Estado, sus órganos, sus agentes, y todos aquellos que actúan en su nombre. En este orden de ideas, la norma interamericana es jus cogens, donde se parte de la premisa hipotética aceptada y reconocida por la comunidad internacional de Estados en su conjunto como norma que no admite acuerdo en sentido contrario, y que solo puede ser modificada por una norma ulterior de derecho internacional general que tenga el mismo carácter.

El "control difuso de convencionalidad si bien se ejerce por todos los jueces nacionales, tiene diferentes grados de intensidad y realización, de conformidad con el marco de sus respectivas competencias y de las regulaciones procesales correspondientes". En principio, corresponde a todos los jueces y órganos jurisdiccionales realizar una "interpretación” de la norma nacional a la luz de la Convención Americana, de sus protocolos adicionales (y eventualmente de otros tratados), así como de la jurisprudencia de la Corte IDH y siempre con la regla interpretativa del principio pro homine a que refiere el artículo 29 del Pacto de San José” (caso Cabrera García Montiel vs. México, 2010, p. 41). 
Ahora bien, la labor administrativa no es ajena a aplicar el control difuso de convencionalidad, así esta posición garantista sea proclive a endilgar que el concepto de la supremacía de la convención es obligatorio en su estatuto normativo, y su precedente parece un nuevo juego de roles donde el derecho de los jueces es transnacional, y la garantía convencional es universal.

\section{COMENTARIOS FINALES A LA GARANTIA CONVENCIONAL EN EL MARCO DE LA PROTECCIÓN DEL INTERÉS DIFUSO: DE LA PROPIEDAD EN COMUNIDADES INDIGENAS}

Pese a que la Convención Americana de Derechos Humanos no ha tenido en sus protocolos un catálogo de protección de intereses difusos, o como lo señala Lorenzetti de derechos de incidencia colectiva, estos son indispensables para la supervivencia humana.

La protección en diferentes modelos nacionales-internacionales existe frente a los Derechos Humanos, pero pese a este esfuerzo de los esquemas normativos se deja entrever que gracias al fortalecimiento del control de convencionalidad los Estados desconocen en contra mayoritariamente los interés difusos, sociales, culturales y espirituales, como el de las comunidades indígenas.

Para el efecto, la Corte Interamericana en el caso Mayagna (sumo) Awas Tingni vs. Nicaragua (2001) se declara:

El artículo 21 de la Convención protege el derecho a la propiedad en un sentido que comprende, entre otros, los derechos de los miembros de las comunidades indígenas en el marco de la propiedad comunal, la cual también está reconocida en la Constitución Política de Nicaragua. Entre los indígenas existe una tradición comunitaria sobre una forma comunal de la propiedad colectiva de la tierra, en el sentido de que la pertenencia de esta no se centra en un individuo sino en el grupo y su comunidad. Los indígenas por el hecho de su propia existencia tienen derecho a vivir libremente en sus propios territorios; la estrecha relación que los indígenas mantienen con la tierra debe 
de ser reconocida y comprendida como la base fundamental de sus culturas, su vida espiritual, su integridad y su supervivencia económica. Para las comunidades indígenas la relación con la tierra no es meramente una cuestión de posesión y producción sino un elemento material y espiritual del que deben gozar plenamente, inclusive para preservar su legado cultural y transmitirlo a las generaciones futuras (p. 120).

Lo anterior permite afirmar un precedente vinculante a nivel internacional en el sistema interamericano, que implica un ejemplo de los intereses difusos, como lo es la propiedad en las comunidades indígenas, y que se constituye en una de las últimas grandes revoluciones en el derecho internacional de los derechos humanos

Gracias a la declaración de los pueblos indígenas y la observación general número 14 del Comité DESC, se tuvo en cuenta la progresividad del derecho internacional de los pueblos indígenas y señaló el surgimiento de un derecho, y una práctica internacional específica, aplicable a los pueblos indígenas, que quedó expresada en la adopción de diversas normas y resoluciones.

El principio de propiedad comunal corresponde a tres ámbitos: a) funcional: el asentamiento de la comunidad a sus raíces ancestrales, culturales, ideológicas y familiares que encubran la forma de convivencia social con el Estado; b) técnica: el consentimiento o consulta que debe solicitar el Estado para realizar cualquier observancia o explotación de sus recursos ecológicos o culturales y c) material: el acceso a los recursos sencillos y efectivos que tienen las comunidades para solicitar la reclamación a las autoridades cuando esto no se cumpla.

La Corte Interamericana, en el caso indigena Sawhoyamaxa vs. Paraguay (2006) se declara:

En consecuencia, la estrecha vinculación de los pueblos indígenas con sus tierras tradicionales y los recursos naturales ligados a su cultura que ahí se encuentren, así como los elementos incorporales que se desprendan de ellos, deben ser salvaguardados por el artículo 21 de la Convención Americana. Al respecto, en otras oportunidades, este Tribunal ha considerado que el término 
"bienes" utilizado en dicho artículo 21, contempla "aquellas cosas materiales apropiables, así como todo derecho que pueda formar parte del patrimonio de una persona; dicho concepto comprende todos los muebles e inmuebles, los elementos corporales e incorporales y cualquier otro objeto inmaterial susceptible de tener un valor", además porque constituyen un elemento integrante de su cosmovisión, religiosidad y, por ende, de su identidad cultural. De lo anterior se concluye que: 1) la posesión tradicional de los indígenas sobre sus tierras tiene efectos equivalentes al título de pleno dominio que otorga el Estado; 2) la posesión tradicional otorga a los indígenas el derecho a exigir el reconocimiento oficial de propiedad y su registro; 3) los miembros de los pueblos indígenas que por causas ajenas a su voluntad han salido o perdido la posesión de sus tierras tradicionales mantienen el derecho de propiedad sobre las mismas, aun a falta de título legal, salvo cuando las tierras hayan sido legítimamente trasladas a terceros de buena fe; y 4) los miembros de los pueblos indígenas que involuntariamente han perdido la posesión de sus tierras, y estas han sido trasladas legítimamente a terceros inocentes, tienen el derecho de recuperarlas o a obtener otras tierras de igual extensión y calidad (p. 250).

En concordancia con lo dispuesto anteriormente, la Corte Interamericana en el caso de la comunidad indigena de Yakie Axa vs. Paraguay (2005) se declara:

La garantía del derecho a la propiedad comunitaria de los pueblos indígenas debe tomar en cuenta que la tierra está estrechamente relacionada con sus tradiciones y expresiones orales, sus costumbres y lenguas, sus artes y rituales, sus conocimientos y usos relacionados con la naturaleza, sus artes culinarias, el derecho consuetudinario, su vestimenta, filosofía y valores. En función de su entorno, su integración con la naturaleza y su historia, los miembros de las comunidades indígenas transmiten de generación en generación este patrimonio cultural inmaterial, que es recreado constantemente por los miembros de las comunidades y grupos indígenas. La Corte considera que este hecho ha afectado el derecho a una vida digna de los miembros de la Comunidad, ya que los ha privado de la posibilidad de acceder a sus medios de subsistencia tradicionales, así como del uso del disfrute de los recursos 
naturales necesarios para la obtención de agua limpia y para la práctica de la medicina tradicional de prevención y cura de enfermedades (p. 168).

De acuerdo a lo anterior la propiedad comunal es una garantía que es inherente a la generalidad, inalienable e inembargable siendo un reconocimiento al derecho internacional de los derechos humanos de las comunidades indígenas y triviales, cuando esta rińe con el concepto de propiedad privada; y en este sentido, el Estado tiene el deber de consultar al pueblo mediante cualquier actividad administrativa o legal so pena de que sea declarado responsable por hecho ilícito internacional, aspecto que reafirma el convenio 169 de 1989 de la O.I.T sobre pueblos indígenas y triviales, y que se constituye en el sustento jurídico y material para la promoción estableciendo el bloque de convencionalidad y la garantía de protección.

Lo anterior es necesario ya que en la sociedad americana confluyen una variedad de culturas y pueblos triviales que hacen indispensable el reconocimiento del precedente obligatorio de la Corte Interamericana de Derechos Humanos frente al respeto de los pueblos ancestrales.

\section{ConClusiones}

La jurisprudencia ha determinado que la protección a la identidad cultural de las comunidades indígenas es un derecho fundamental, cuyo reconocimiento está orientado a lograr la preservación de tales culturas. Lo anterior supone participación de la comunidad indígena en la adopción de las decisiones que les conciernen, y en especial en las relativas a la explotación de los recursos naturales ubicados en sus territorios.

La consulta, como mecanismo de participación en la adopción de decisiones y de garantía de la identidad cultural de los pueblos indígenas y tribales, es obligatoria en cuanto a su verificación, pero no sustrae de la competencia de las autoridades la adopción final de la medida legislativa o administrativa, como en general sucede con todos los mecanismos de concertación. 


\section{REFERENCIAS}

Albanese, S. (2011). Opiniones consultivas y observaciones generales, control de convencionalidad. La jurisprudencia internacional y los diversos alcances de los preceptos convencionales. Editorial Ediar. Buenos Aires, Argentina

Bidart, G. (1994). La interpretación del sistema de derechos humanos. Editorial Ediar. Buenos Aires, Argentina

Bobbio, N. (1992). Teoría general del Derecho. Editorial Temis. Bogotá, Colombia

Comella, V. (2011). Una defensa del modelo europeo del control de constitucionalidad. Editorial Marcial Pons.

Corte Interamericana de Derechos Humanos. (2010). Caso Cabrera García Montiel Flores vs. México. Sentencia 26 de noviembre de 2010, voto razonado. Eduardo Ferrer Mac Gregor-Pisot.

Corte Interamericana de Derechos Humanos. (2011). Caso Gelman vs. Uruguay. Sentencia 24 de febrero de 2011. Reparaciones y Costas.

Corte Interamericana de Derechos Humanos. (2007). Caso Myrna Mack Chang vs. Guatemala. Sentencia 25 de noviembre de 2007 . Voto concurrente Sergio García Ramírez.

Corte Interamericana de Derechos Humanos. (2011). Caso Vera vs. Ecuador. Sentencia 19 de mayo de 2011. Excepción preliminar, fondo reparaciones y costas.

Corte Interamericana de Derechos Humanos. (2011). Caso de la comunidad Mayagna (sumo) Awas Tingni vs. Nicaragua. Sentencia 31 de agosto de 2001. Excepción preliminares, fondo reparaciones y costas.

Corte Interamericana de Derechos Humanos. (2006). Caso comunidad indígena Sawhoyamaxa vs. Paraguay. Sentencia 29 de marzo de 2006. Excepción preliminares, fondo reparaciones y costas. 
Corte Interamericana de Derechos Humanos. (2012). Caso pueblo indigena Kichwa de Sarayaku vs. Ecuador. Sentencia 27 de junio de 2012. Excepción preliminares, fondo reparaciones y costas.

Corte Constitucional de Colombia. (1997). M.P Antonio Barrera Carbonell. Sentencia SU 039-1997.

Corte Constitucional de Colombia. (1997). M.P. Marco Gerardo Monroy Cabra. Sentencia C-620 de 2003.

Corte Constitucional de Colombia. (2009). M.P Nilson Pinilla Pinilla. Sentencia T-769 de 2009.

Corte Constitucional de Colombia. (1998). M.P José Gregorio Hernández Galindo. Sentencia T-525 de 1998.

De la Guardia, E. (1997). Derecho de los tratados Internacionales. Editorial Ábaco de Rodolfo Depalma.

Dromi, R. (1992). Los jueces, ¿es la justicia un tercio del poder? Editorial Ciudad Argentina.

Ferrer, E. (2010). El control difuso de convencionalidad en el estado constitucional. Recuperado de http://www.juridicas.unam.mx

Fundación Civitas Firma. (s.f.). Derechos Humanos. Carta Africana sobre los Derechos Humanos $y$ de los Pueblos (Carta de Banjul). Recuperado de http://fundacioncivitas.org/2006/10/ carta-africana-sobre-los-derechos-humanos-y-de-los-pueblos-carta-de-banjul/

Gozaini, O.(2006). Introducciónalderecho ProcesalConstitucional. Editorial Rubinzal-Culzoni.

Quinche, M. F. (2010). Derecho Constitucional Colombiano. Editorial Ediciones Doctrina y Ley. 
Quiroga, C. (2005). La Convención americana teoría y jurisprudencia. Vida, integridad personal, libertad personal, debido proceso y recurso judicial. Editorial Centro de Derechos Humanos Facultad de Derecho de la Universidad de Chile.

Sagués, N. P. (2002). Derecho Procesal Constitucional. Recurso extraordinario, (1). Editorial Astrea.

Sola, J. V. (2001). Control judicial de constitucionalidad. Editorial Abeledo- Perrot.

Vidart, D. (1968). Ideología y realidad de América. Universidad República de Montevideo.

Zimerman, S. (2011). Opiniones consultivas y observaciones generales, control de convencionalidad. Editorial Ediar. 